\title{
Biogenic Synthesis of Selenium Nanoparticles with Edible Mushroom Extract: Evaluation of Cytotoxicity on Prostate Cancer Cell Lines and Their Antioxidant, and Antibacterial Activity
}

\author{
Suvardhan Kanchi ${ }^{1}$ (D), Inamuddin ${ }^{2, *}$ (D), Anish Khan ${ }^{2}$ (D) \\ 1 Department of Chemistry, Faculty of Applied Science, Durban University of Technology, Durban, 4000 South Africa; \\ ksuvardhan@gmail.com \\ 2 Chemistry Department, Faculty of Science, King Abdulaziz University, Jeddah 21589, Saudi Arabia; \\ inamuddin@zhcet.ac.in; anishkhan97@gmail.com; \\ * Correspondence: inamuddin@zhcet.ac.in;
}

Scopus Author ID 57215776379

Received: 5.05.2020; Revised: 22.05.2020; Accepted: 23.05.2020; Published: 27.05.2020

\begin{abstract}
We report edible mushroom extract (EME) as a robust and environmentally friendly precursor for the biogenic synthesis of selenium nanoparticles (SeNPs). The as-synthesized SeNPs were characterized by UV-visible spectrophotometer (UV-vis), Fourier-transform infrared spectroscopy (FTIR), Transmission electron microscope (TEM), and Dynamic light scattering (DLS) techniques. The results obtained from TEM and DLS suggested that the SeNPs synthesized with EME are in the size of $\sim 8 \mathrm{~nm}$ with a spherical shape and monodispersity. The occurrence of antioxidants in the EME has been confirmed with FTIR and thereby confirmed that flavonoids and phenolic compounds played a pivotal role in the biosynthesis of SeNPs from $\mathrm{Na}_{2} \mathrm{SeO}_{3}$. In addition, EME-SeNPs exhibited no cytotoxicity on the cell lines of prostate cancer (PC-3) at concentrations ranging from 0.5-1.5 $\mu \mathrm{M}$. At a concentration of $0.25 \mathrm{mM}$ against 1,1-diphenyl-2-picrylhydrazyl, the average scavenging level of EME-SeNPs was found to be $>80.20 \%$. Moreover, the percentage viability of gram-negative E.coli and gram-positive E.faecium was recorded at a high concentration of EME-SeNPs and found to be 82 $\%$ and $65 \%$, respectively.
\end{abstract}

Keywords: SeNPs; Edible mushroom extract; Prostate cancer cell lines; Antioxidant and antibacterial activities.

(C) 2020 by the authors. This article is an open-access article distributed under the terms and conditions of the Creative Commons Attribution (CC BY) license (https://creativecommons.org/licenses/by/4.0/).

\section{Introduction}

Mushrooms were considered to be one of the most significant ingredients of epicurean cookery throughout the globe, particularly for their unique flavor, and were regarded as a culinary wonder by humankind. There are more than 2,000 species of mushrooms in nature, but only 25 are commonly recognized as food, and few are cultivated commercially [1,2]. Furthermore, it is demonstrated that mushroom has significant medical properties, including detoxification, antiallergic, antiparasitic, hepatoprotective, antifungal, antioxidant, antibacterial, antidiabetic, cardiovascular effects, and name a few [3-6].

There has been a remarked increase in the field of nanoparticle synthesis in the last decade, with meticulous morphologies and outstanding structures, making it a large area of study. The synthesis of nanoparticles (NPs) with specific particle size, shape, and their 
crystalline structure is one of the greatest objectives in the material science and technology for the effective use in the biosensor, bio-medical applications for fabrications in the development of cost-effective electrode systems [7-9]. Nanoparticles (NPs) with at least one dimension below $100 \mathrm{~nm}$, including nanotubes, nanosheets, and nanowires, have gained substantial consideration due to their wide range applications [10-12]. NPs act as a bridge between bulk materials and atomic or molecular structures, in addition to their unique chemical and physical properties. Hence, these are promising materials for a variety of applications in various fields such as in medicine, electrochemistry, inorganic chemistry, biotechnology, and analytical chemistry for the detection of analytes of interest [13-16].

For the preparation of NPs with diverse morphology and scale, different synthetic methods were used. Though these methods have resulted in unique featured NPs, a significant improvement in the synthesis methodology is necessary to build quality and long-lasting materials for innovative domestic, communication, transport, medical, agricultural, and industrial applications. Thus, the main emphasis is on developing NPs using environmentally sustainable strategies. Nature has been providing ways and perceptions into advanced nanomaterial synthesis. The literature has now stated that biological systems can serve as the "biological laboratory" for the development of different metal/metal oxide particles [17-23].

Selenium is a well-known significant element used in various research fields such as the energy sector and semiconductor industry due to its unique physical, optical and chemical properties [24]. Due to their minimal risk compared with selenium alone, selenium nanoparticles (SeNPs) have recorded substantial medical diagnostic applications in the current decade in the treatment of leukemia [25-36] and used as dietary supplements due to their rich availability of antioxidants [37]. In general, the popular industrial techniques used in the selenium based nanomaterials synthesis encompass multifaceted mechanisms linked to enormous environmental jeopardies such as high temperature and pressure. Recent literature, however, documented the green synthesis of metal nanoparticles by advancing morphology and nanoparticle size [38-40].

The use of plant-based natural materials in the biogenic synthesis of NPs can be beneficial over other chemical or biological processes due to their environmentally friendly nature [41-44]. Whereas conventional synthesis methods involve the utilization of huge temperature and pressure, resulting in the cost implications; therefore, this study was aimed at exploring the anti-carcinogenic impact of SeNPs on prostate cancer, as well as antibacterial activity on gram-negative and positive bacteria, biogenic synthesis of SeNPs were prepared using an edible mushroom extract. The as-prepared EME-SeNPs were characterized by UVvisible, TEM, and DLS techniques.

\section{Materials and Methods}

\subsection{Chemicals and reagents.}

All chemicals were of analytical grade and used as received without further purification. Sodium selenite ( $\geq 98.0 \%$ ), 1,1-diphenyl-2-picrylhydrazyl (DPPH) ( $>99.5 \%$ ), Sodium borate, Sodium hydroxide, and hydrochloric acid were purchased from Sigma-Aldrich, South Africa. The edible mushrooms were purchased from the local supermarket, Durban, South Africa. Throughout this study, ultra-pure water $(\geq 18.2 \mathrm{~m} \Omega \mathrm{cm}$, Milli-Q, Millipore) was used. 


\subsection{Instrumentation.}

UV - vis absorption spectra were measured using a $1 \mathrm{~cm}$ quartz cell on the Thermo Evolution 300 Absorption Spectrophotometer. The FTIR and Transmission electron microscopic (TEM) characterization were performed with Perkin-Elmer (USA) and HITACHI H-7650 model systems, respectively. The dynamic light scattering (DLS) measurements were conducted in with Zetasizer (Nano ZS, Malvern Instruments Ltd., UK) and its software.

\subsection{Procurement of edible mushrooms.}

These mushrooms were collected from the local supermarket, cut into small pieces, and washed several times with deionized distilled water. In $500 \mathrm{ml}$ of deionized distilled water, $100 \mathrm{~g}$ of finely cut mushroom was boiled for $15 \mathrm{~min}$ at $60{ }^{\circ} \mathrm{C}$ and filtered. The filtrate is refrigerated to room temperature and used as a reduction agent and stabilizer for the biogenic synthesis of SeNPs.

\subsection{Synthesis of Selenium Nanoparticles (SeNPs)}

Into a $100 \mathrm{ml}$ beaker, $10 \mathrm{ml}$ of $10 \mathrm{mM} \mathrm{Na}_{2} \mathrm{SeO}_{3}$ was added and then placed on a hot plate equipped with a stirrer. To a vigorously stirred (250 rpm) aqueous solution of $\mathrm{Na}_{2} \mathrm{SeO}_{3}$, $5 \mathrm{ml}$ of edible mushroom extract (EME) was added dropwise using a burette for $5 \mathrm{~min}$. Then the $\mathrm{pH}$ of the reaction mixture was adjusted to $\mathrm{pH} 9.2$ with $1 \mathrm{M} \mathrm{HCl} / \mathrm{NaOH}$ and allowed stirring for $70 \mathrm{~h}$. Initially, the reduction process takes place slowly by changing the slight yellowcolored solution into orangish-red, and the color remains unchanged at the end of the third day. This confirms the completeness of the reduction process with stable SeNPs as a colloidal solution. The schematic illustration of the biogenic synthesis of SeNPs with EME was represented in Scheme 1.

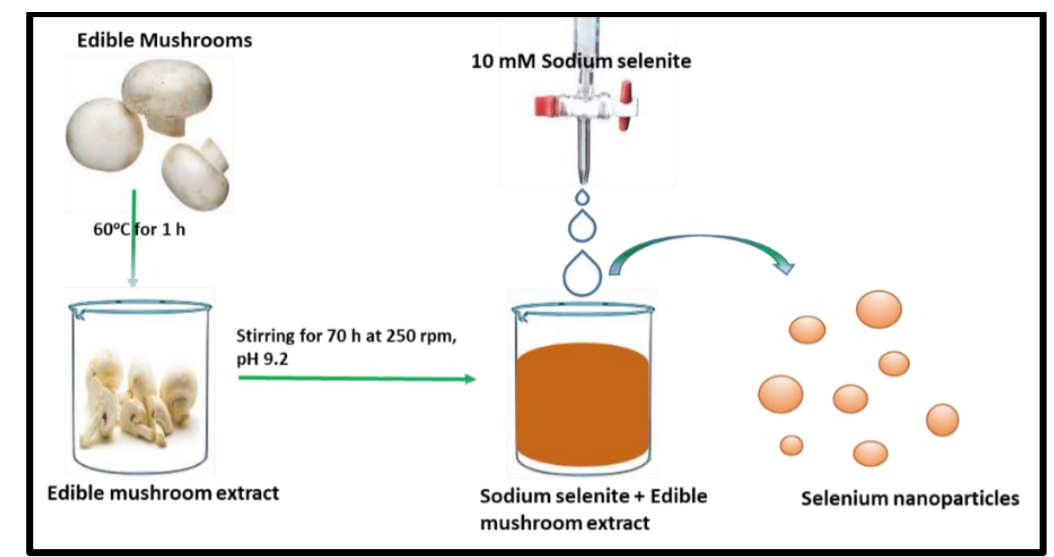

Scheme 1. Schematic illustration of biogenic synthesis of SeNPs with EME.

\subsection{Cytotoxicity assessment of EME-SeNPs.}

In this study, prostate cancer cell lines (cas: 90112714) extracted from Caucasian prostate adenocarcinoma were purchased from Sigma-Aldrich, United States of America. These cell lines were cultured in a mixture of $2 \mathrm{mM}$ Glutamine, Coons Modified Ham's F12, 7 \% Foetal Bovine Serum (FBS) or Kaign's modified Ham's F12, $18 \mathrm{mg} \mathrm{l}^{-1}$ Inositol, $45 \mathrm{mg} \mathrm{l}^{-1}$ ascorbic acid, $1 \%$ antibiotic mixture (penicillin, and streptomycin) and $7 \%$ Foetal Bovine Serum (FBS) in a $5 \% \mathrm{CO}_{2}$ cultivated to $85 \%$ confluence at $37^{\circ} \mathrm{C}$. Later this mixture was exposed to various concentrations of SeNPs on subconfluent cells. Inverted microscope (IX- 
73, Olympus, South Africa) was used to visualize the obtained results of cell confluences. Control and treatment cells were exposed after $2 \mathrm{~h}$ and monitored the cytotoxic effect of SeNPs on prostate cancer (PC-3) cells by cell density measurement using a Neubauer chamber.

\subsection{Assessment of antioxidant activity of EME and EME-SeNPs.}

The free radical scavenging activity of the SeNPs was measured using DPPH as a free radical model as per the reported method [22]. In brief, different volumes of EME-SeNPs (1.0 - $0.5 \mathrm{ml})$ or control and deionized distilled water $(1.0-2.0 \mathrm{ml})$ were added and mixed vigorously to a $3.0 \mathrm{ml}$ of $0.3 \mathrm{mM}$ of DPPH in absolute methanol. The mixture was further sonicated at room temperature for $15 \mathrm{~min}$ to boost the surface reaction between the DPPH reagent and EME-SeNPs and kept in the dark. The supernatant was collected after centrifugation at 10,000 rpm, and absorbance estimated at $340 \mathrm{~nm}$. In this study, DPPH control was considered as a reference. Using the below equation, the free radical scavenging activity was measured:

$$
\text { Scavenging activity }(\%)=\left[1-\frac{\text { Absorbance of sample }}{\text { Absorbance of control }}\right] \times 100
$$

\subsection{Assessment of antibacterial activity using standard plate count colony and forming units} (CFU) measurement methods.

In this study, the standard count method was used to monitor the viability of SeNPs with untreated and treated E. coli cultures. Initially, E.coli ATCC 25922 and E. faecium ATCC 35667 were cultivated to O.D of 0.5 at $500 \mathrm{~nm}$ at $35^{\circ} \mathrm{C}$ and $\mathrm{CFU} \mathrm{ml}{ }^{-1}$ of 105 . Then these cells were centrifuged at $4{ }^{\circ} \mathrm{C}$ with a $4000 \mathrm{rpm}$ for $5 \mathrm{~min}$ to undergo palletization. After this process, cells were given several washes with phosphate buffer saline (PBS) of $\mathrm{pH}$ 7.4. Finally, to this PBS solution, various concentrations of SeNPs colloidal solution $(10,25,50,75$, and $100 \mu \mathrm{g}$ $\mathrm{ml}^{-1}$ ) with EME and without EME to investigate the antibacterial effect. Bacterial culture has acted as a negative control in the Luria Bertani (LB) broth without SeNPs. The cells were cultivated at $35^{\circ} \mathrm{C}$ for $120 \mathrm{~min}$ and were diluted serially at $\mathrm{pH} 7.0$ in PBS. The dilutions were impregnated on the plats of LB agar. The number of CFUs has been manually counted after overnight incubation at $37{ }^{\circ} \mathrm{C}$. All the experiments were conducted in triplicate.

\section{Results and Discussion}

\subsection{UV-visible spectrophotometer analysis.}

Green chemistry owes considerable importance to the synthesis of metal nanoparticles (MNPs) due to their infinite applications [45]. Metal nanoparticles are readily discernible due to differences in solution color. Due to the peak locations and sphere, the UV-vis absorbance spectroscopy has proven to be a very useful technique for studying MNPs being sensitive to particle size. The bioactive molecules in the EME, however, reduce the precursor to form SeNPs, which have been further confirmed by UV-vis, FTIR, DLS, and TEM. The $10 \mathrm{mM}$ of $\mathrm{Na}_{2} \mathrm{SeO}_{3}$ with EME started changing color from yellow to orangish-red color after constant stirring for $70 \mathrm{~h}$ at room temperature, resulted in a bright and high-intensity solution. The color of the obtained solution remained unchanged throughout the experimental period, which was indicative of a complete reduction of Se ions into SeNPs at $\mathrm{pH}$ 9.2.

Figure 1 depicts the UV-visible spectrum of SeNPs, EME, and EME-SeNPs. Though the solution of $\mathrm{Na}_{2} \mathrm{SeO}_{3}$ was colorless, the weak absorption peak at $280 \mathrm{~nm}$ was observed, but 
in the case of EME, the color of the solution was slight yellow with an $\lambda \max$ of $300 \mathrm{~nm}$. The addition of aqueous EME to $10 \mathrm{mM}$ of $\mathrm{Na}_{2} \mathrm{SeO}_{3}$ at $\mathrm{pH} 9.2$ resulted in the color change from slightly yellow to orangish-red with an $\lambda_{\max }$ of $340 \mathrm{~nm}$ due to the excitation of surface plasmon resonance. Generally, the increase in the concentration of capping agent increases the metallic nature of SeNPs and reduction of particle size [46].

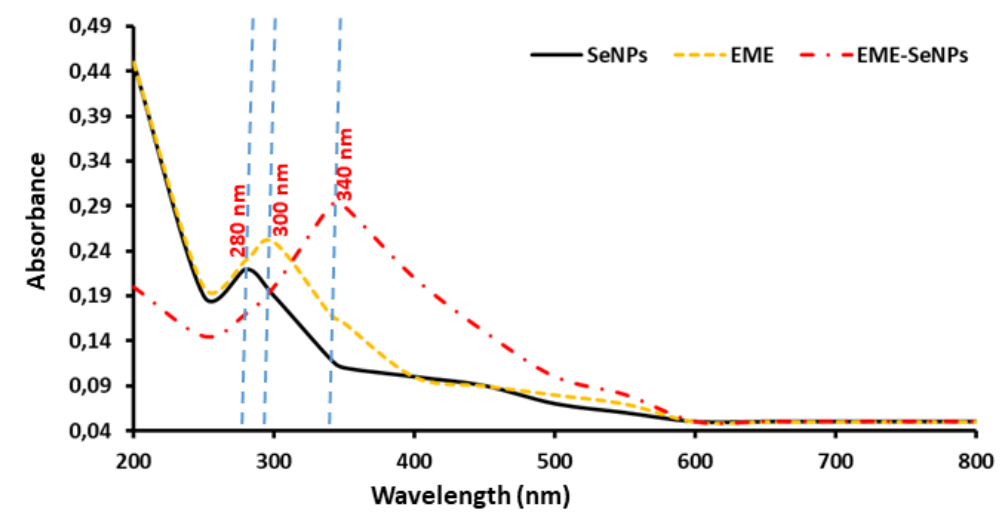

Figure 1. UV-visible spectrophotometric spectrum of SeNPs, EME, and EME-SeNPs.

\subsection{FTIR analysis.}

Figure 2 illustrates the FTIR spectrum of EME and EME-SENPs. The obtained results reveal that several absorption peaks at $1250,1658,2230$, and $3610 \mathrm{~cm}^{-1}$ were observed due to the ester bonds in EME. The small and broad peak at $1250 \mathrm{~cm}^{-1}$ corresponded to the carbonyl, $-\mathrm{NH}$, and $-\mathrm{NH}_{2}$ functional groups. The sharp and high-intensity narrow peak at $1658 \mathrm{~cm}^{-1}$ was attributed to amide-I, resulted in the stretching of carbonyl bonded protein present in the EME. This amide-I group would interact with SeNPs and form a strong layer around the nanoparticles, leading to the monodisperse of the SeNPs in aqueous medium [47]. The lowintensity amide-I group peak at $1690 \mathrm{~cm}^{-1}$ in the EME-SeNPs confirms the interaction of SeNPs with the proteins of the EME. The peaks at $2230 \mathrm{~cm}^{-1}$ and $3610 \mathrm{~cm}^{-1}$ attributed to the $\mathrm{C}=\mathrm{N}$ bond and $-\mathrm{OH}$ stretching. The broad peak of $-\mathrm{OH}$ group at $3610 \mathrm{~cm}^{-1}$ confirms the involvement of carbohydrates, phenolic acids, proteins, flavonoids, and tannins in the reduction of Se ions to SeNPs [48].

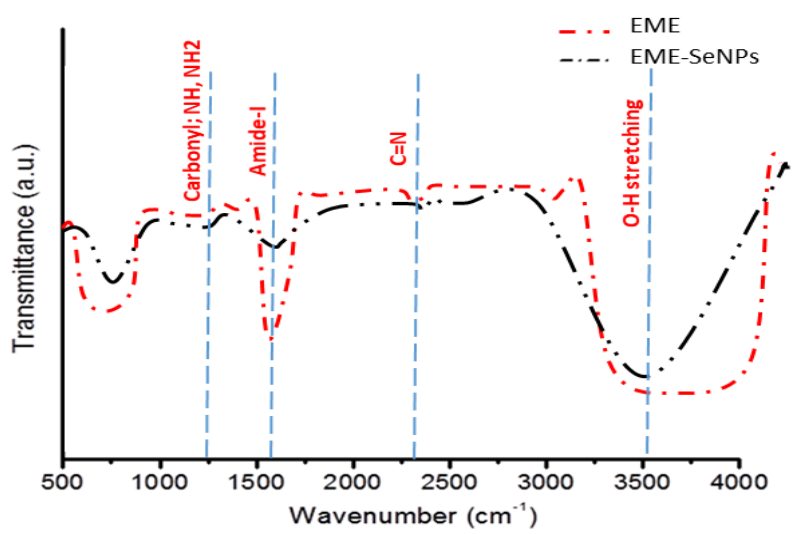

Figure 2. FTIR spectrum of EME and EME-SeNPs.

\subsection{TEM analysis.}

Figure 3A-B, represents the surface morphology evaluation of the EME mediated SeNPs. Figure 3A shows the shape and distribution of SeNPs, indicating the formation of spherical and monodispersed SeNPs using one-pot biogenic synthesis with EME. The obtained 
SeNPs size was recorded and found to be $\sim 8 \mathrm{~nm}$ as per the Figure $3 \mathrm{~A}$ inset distribution graph. Figure 2B demonstrates the HR-TEM image of the biogenic synthesis of SeNPs, resulted in the visualization of lattice fringes on the surface of the SeNPs. The lattice fringes depict a spacing of $0.252 \mathrm{~nm}$, which corresponds to the spacing between $\left(\begin{array}{lll}1 & 0 & 1\end{array}\right)$ plane, indicating the highly crystalline nature of the SeNPs. The DLS measurements were performed, and the hydrodynamic size of the SeNPs was recorded as $18 \mathrm{~nm}$, which is in alignment with TEM results.

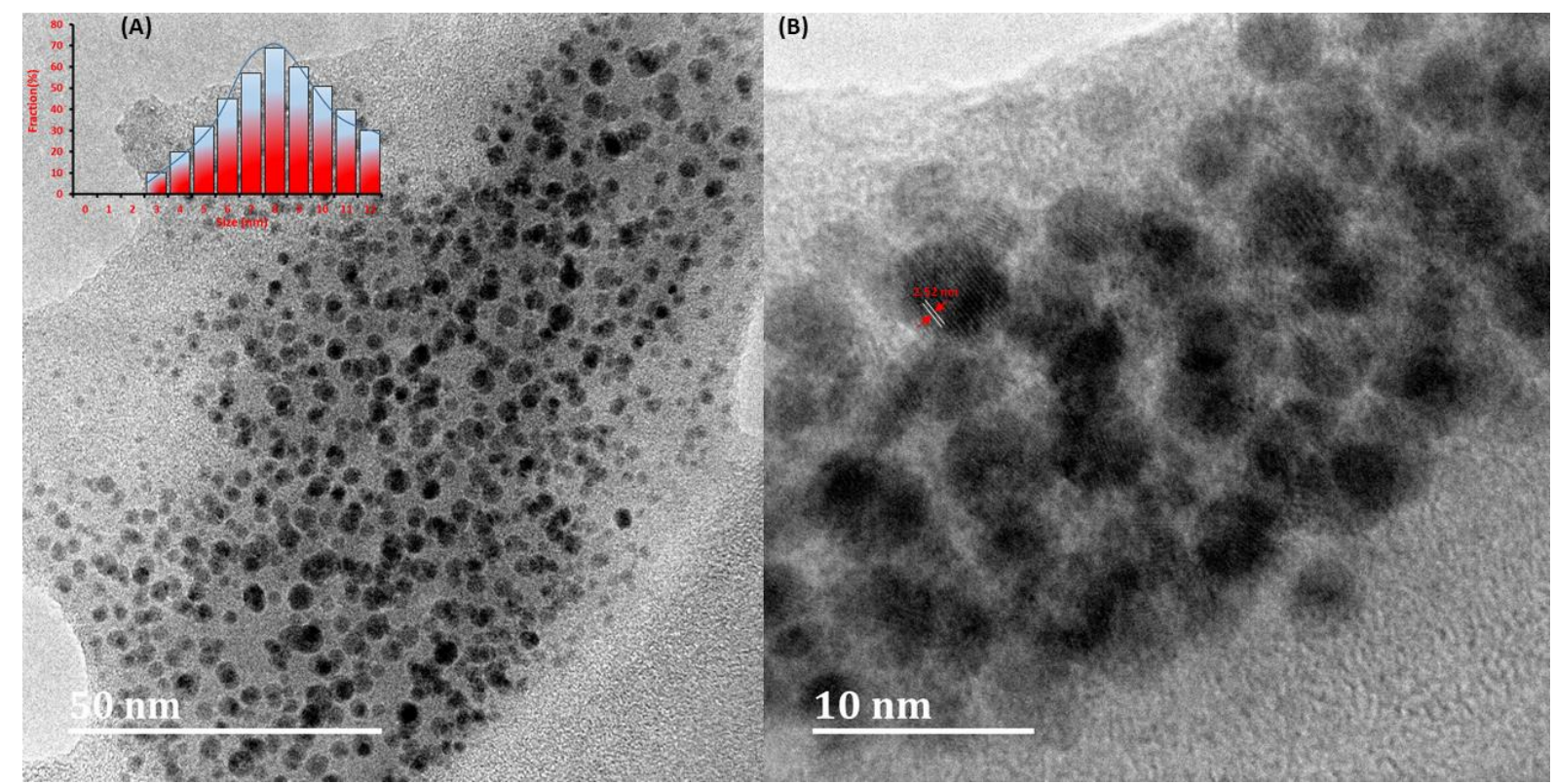

Figure 3. TEM and HR-TEM images are showing the monodispersity of (A) SeNPs (B) Fringes with a lattice spacing of $2.52 \mathrm{~nm}$.

\subsection{Effect of CuNPs on prostate cancer (PC-3) cell proliferation.}

Edible mushroom extraction is rich in antioxidant properties and is therefore chosen as a precursor to greener SeNP synthesis [49].

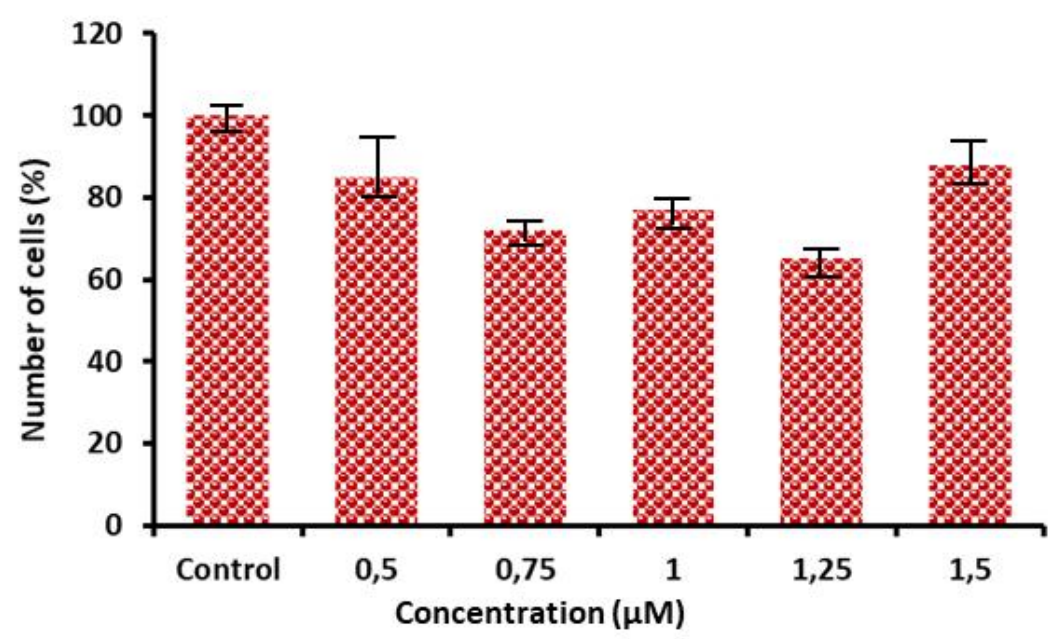

Figure 4. Histogram of cellular densities of PC-3 demonstrating the effect of different concentrations of EMESeNPs.

The cytotoxic in-vitro studies were assessed by measuring changes in cell density following exposure to NPs at various concentrations $(0.5-1.5 \mu \mathrm{M})$. As shown in Figure 4, the cells displayed excellent viability in the presence of NPs up to $1.5 \mu \mathrm{M}$, which suggests that the SeNPs had no toxic effect. The results obtained indicate that after $2 \mathrm{~h}$ of the exposure period, 
there is no cytotoxicity of NPs on prostate cancer (PC-3) cells in the range of $1.5-0.5 \mu \mathrm{M}$. The results obtained indicate no significant change was observed against the control. This action of SeNPs can be attributed to its functionality of phenolic molecules from the EME. It was demonstrated that the exposure time plays a key role in in-vitro studies as it influences the cell's penetration distance to determine cytotoxic studies' effectiveness. Hence, the exposure time to SeNPs with the cell was standardized as $2 \mathrm{~h}$ to reach the inner layers of the cell to exhibit cytotoxicity.

\subsection{Antioxidant activity.}

DPPH is a solid, nitrogen-centric, free radical whose color changes from slightly yellow to orangish-red when either the hydrogen or electron donation process is reduced. Radical scavengers are the substances capable of conducting this reaction due to antioxidants nature. The DPPH offers a stress-free and fast method for assessing antioxidant activity. Edible mushroom extract-SeNPs under analysis, radical scavenging activity decreased with an increase in the concentration, demonstrating that this process is a concentration-dependent phenomenon. The percentage of radical scavenging activity for DPPH inhibition was illustrated in Figure 5. The obtained results demonstrated that the percentage of DPPH radical scavenging activity inhibition had been decreased by an increase in the dosage of EME-SeNPs due to the sparing solubility of SeNPs and inadequate DPPH content at higher concentrations. It was suggested that the EME scavenging efficacy has no significant effect at a maximum percentage. However, EME-SeNPs were found to be $81.25 \%, 73.42 \%, 37.38 \%$ and $28.97 \%$ at $0.25 \mathrm{mM}$, $0.50 \mathrm{mM}, 0.75 \mathrm{mM}$, and $1.0 \mathrm{mM}$ respectively. This phenomenon could be due to the fact that EME acts as a robust oxidizing agent and loses electrons easily compared to EME-SeNPs [50].

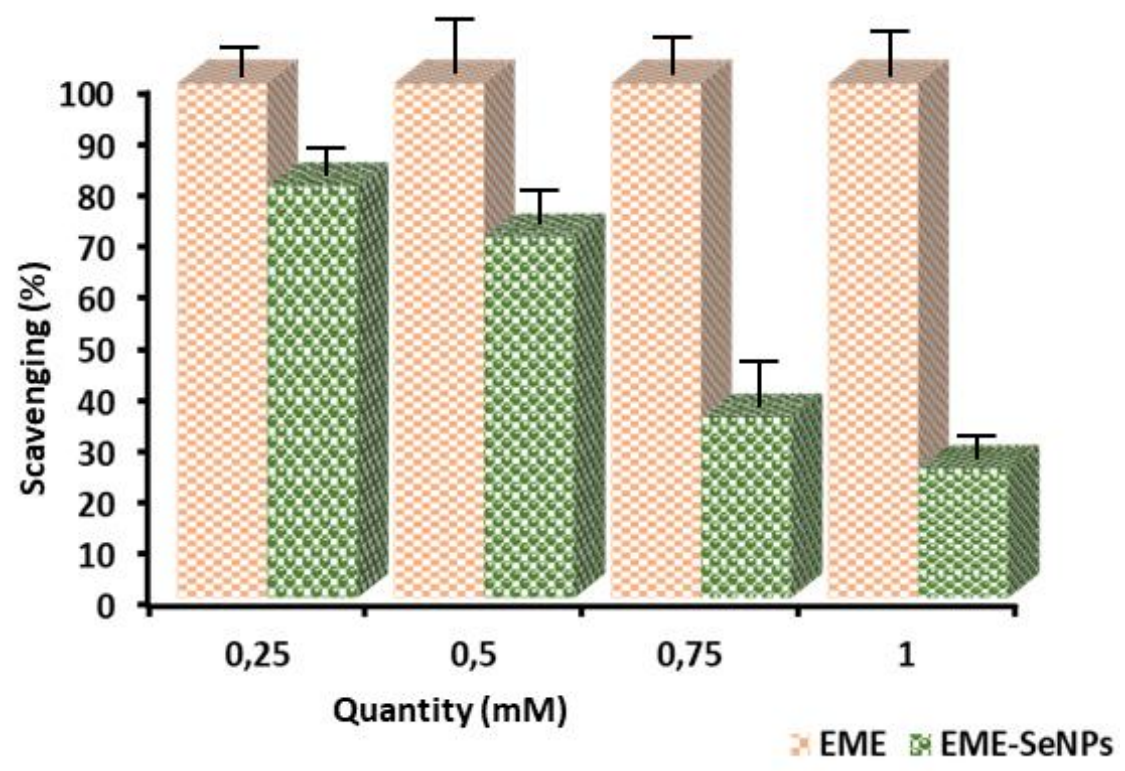

Figure 5. Graph illustrating the antioxidant activity of EME and EME-SeNPs.

\subsection{Enhanced antibacterial activity of biogenic synthesized EME-SeNPs.}

The antibacterial behavior of SeNPs was investigated with the bacterial culture of gramnegative and gram-positive by varying concentrations of NPs, ranging from 10-100 $\mathrm{g} \mathrm{ml}^{-1}$. The percentage of viability was studied using the standard method of plate counting. As the concentration of SeNPs increased, the count of bacterial colony-forming units (CFU) of gramnegative (E. coli) and gram-positive (E. faecium) cultures decreased in the plate count 
methodology. Figure 6A-B illustrate the antibacterial activity of EME-SeNPs synthesized using the edible mushroom extract. This study was performed with EME and EME-SeNPs. Initially, various concentrations of EME-SeNPs ranging from 10-100 $\mu \mathrm{g} \mathrm{ml}^{-1}$ was used to monitor the viability percentage of E.coli and E. faecium The SeNPs viability percent demonstrated greater antibacterial activity compared with gram-positive E. faecium versus gram-negative E. coli. The reported findings were in line with previously published reports [51], suggesting the antibacterial activity of SeNPs. The significant reason for this behavior could be due to the difference between gram-positive and gram-negative bacteria in the cell wall structure. The gram-positive bacteria cell wall usually consists of $80 \%$ of peptidoglycan. On the other hand, Teichoic acids, other proteins, and outer membrane lipopolysaccharides make up the remaining 10-20\% of the cell wall. Whereas, in the case of gram-negative bacteria, the cell wall is made up of $10 \%$ peptidoglycan with outer membrane composition, including $15 \%$ lipoproteins, $35 \%$ phospholipids, and $50 \%$ lipopolysaccharides. The outer membrane in gram-negative bacteria is, therefore, tightly packed, offering defense and immunity to antibacterial agents [52]. In addition, the NPs size plays a pivotal role in the enhanced antibacterial activity and varies the contagion and susceptibility of different strains [53]. Hence, the size of SeNPs synthesized with EME was $\sim 8 \mathrm{~nm}$ when compared to NPs $(\sim 20 \mathrm{~nm})$ synthesized with another sodium borate. It was reported that E. faecium was highly morbific than E. coli. The obtained results from Figure $6 \mathrm{~B}$ revealed that $100 \mu \mathrm{g} \mathrm{ml}^{-1}$ of EME-SeNPs exhibited $82 \%$ and $65 \%$ of viability percentages against E.coli and E. faecium, whereas SeNPs synthesized using sodium borate showed viability percentages of $55 \%$ and $50 \%$. These statistics suggested that the EME-SeNPs have more antibacterial properties compared to SeNPs prepared with other reducing agents.

Moreover, it is noted that there was a statistically important difference in E.coli and E. faecium cell viability at $100 \mu \mathrm{g} \mathrm{ml}^{-1}$ using EME-SeNPs $(\mathrm{p}=0.0435)$. Interestingly, the same pattern results were observed with concentrations of $25 \mu \mathrm{g} \mathrm{ml}^{-1}, 50 \mu \mathrm{g} \mathrm{ml}^{-1}$ and $75 \mu \mathrm{g} \mathrm{ml}^{-1}$ of EME-SeNPs.

(A)

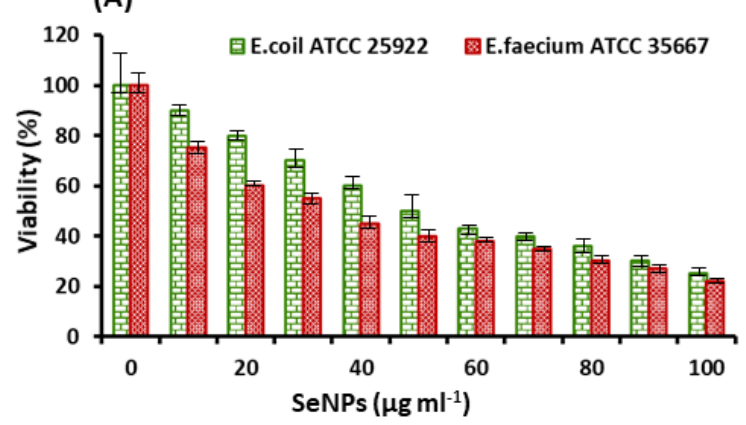

(B)

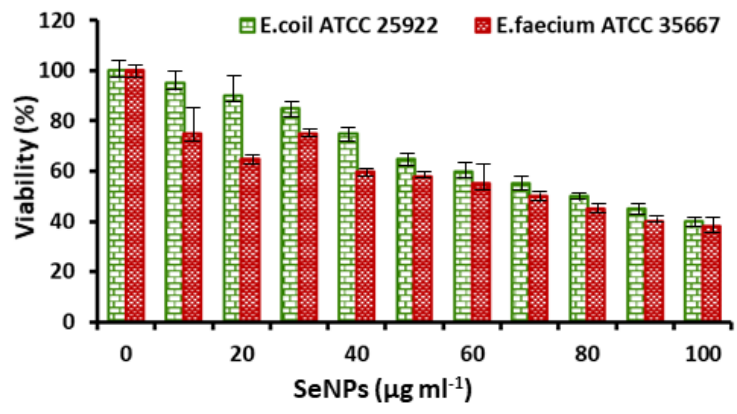

Figure 6. Percentage viability studies of (A) EME-SeNPs (B) SeNPs synthesized without EME against $E$. coli ATCC 25922 and E. faecium ATCC 35667.

\section{Conclusions}

The findings reported in the present research show the biogenic synthesis of SeNPs using the EME with an average size of $\sim 8 \mathrm{~nm}$. The key finding was the presence and detection of flavonoids by FTIR, confirmed their role in the biosynthesis of SeNPs. In addition, the EMESeNPs cytotoxicity results confirmed that there is significant no influence on cell lines (PC-3) of prostate cancer within a concentration range of 0.5-1.5 $\mu \mathrm{M}$. The DPPH assays have shown the highest scavenging effectiveness of EME-SeNPs against antioxidant activity (> 80.0\%). 
The EME based flavonoids anchored SeNPs exhibited excellent antibacterial activity against both gram and positive E. coli and E. faecium, respectively. In the case of E. faecium, the antibacterial activity was noticeable as the EME-SeNPs could simply pierce the outer membrane due to the less compact nature compared with that of E.coli. The biogenic synthesis described here is reproducible, cost-effective, easy to handle, and environmentally friendly manner as it uses EME for the first time in the synthesis of SeNPs.

\section{Funding}

This project was funded by the Deanship of Scientific Research (DSR), King Abdulaziz University, Jeddah, under grant No. G: 168-130-1441. The authors, therefore, gratefully acknowledge DSR technical and financial support.

\section{Acknowledgments}

This project was funded by the Deanship of Scientific Research (DSR), King Abdulaziz University, Jeddah, under grant No. G: 168-130-1441. The authors, therefore, gratefully acknowledge DSR technical and financial support.

\section{Conflicts of Interest}

The authors declare no conflict of interest.

\section{References}

1. Chang, S.T.; Miles, P.G. Mushrooms: Cultivation, Nutritional Value, Medicinal Effect, and Environmental Impact. CRC Press, Boca Raton, Fla, USA, 2nd edition, 2008.

2. Ergönül, P.G.; Akata, I.; Kalyoncu, F.; Ergönül, B. Fatty acid compositions of six wild edible mushroom species. Scientif. World J 2013, 2013, 1-4, https://doi.org/10.1155/2013/163964.

3. Chang, S.T.; Wasser, S.P. The role of culinary-medicinal mushrooms on human welfare with a pyramid model for human health. Int. J. Med. Mushr 2012, 14, 95-134, https://doi.org/10.1615/intjmedmushr.v14.i2.10.

4. Finimundy, T.C.; Gambato, G. R.; Fontana, R.; Camassola, M.; Salvador, M.; Moura, S.; Hess, J.; Henriques, J.A.; Dillon, A.J.; Roesch-Ely, M. Aqueous extracts of Lentinula edodes and Pleurotus sajor-caju exhibit high antioxidant capability and promising in vitro antitumor activity. Nutr. Res 2013, 33, 76-84, https://doi.org/10.1016/j.nutres.2012.11.005.

5. Yu, S.; Weaver, V.; Martin, K.; Cantorna, M.T. The effects of whole mushrooms during inflammation. BMC Immunol 2009, 10, 10-12, https://doi.org/10.1186/1471-2172-10-12.

6. Zhang, L.; Fan, C.; Liu, S.; Zang, Z.; Jiao, L. Chemical composition and antitumor activity of polysaccharide from Inonotus obliquus. J. Med. Plant. Res 2011, 5, 1251-1260.

7. Antonyraj, C.A.; Jeong, J.; Kim, B.; Shin, S.; Kim, S.; Lee, K.Y.; Cho, J.K. 2013. Selective oxidation of HMF to DFF using Ru/calumina catalyst in moderate boiling solvents toward industrial production. J. Ind. Eng. Chem 2013, 19, 1056-1059, https://doi.org/10.1016/j.jiec.2012.12.002.

8. Frances, N.; Nikolay, A.P.; Michael, J.F.B.; Tim, G.; Paul, A.M. Novel one-pot synthesis and characterization of bioactive thiol-silicate nanoparticles for biocatalytic and biosensor applications. Nanotechnology 2009, 20, https://doi.org/10.1088/0957-4484/20/5/055612.

9. Staniland, S.S. Magnetosomes: Bacterial Biosynthesis of Magnetic Nanoparticles and Potential Biomedical Applications. In: Nanotechnologies for the Life Sciences. Wiley-VCH Verlag GmbH \& Co. KGaA. 2007, https://doi.org/10.1002/9783527610419.ntls0173.

10. Fu, H.; Yang, X.; Jiang, X.; Yu, A. Bimetallic Ag-Au nanowires: synthesis, growth mechanism, and catalytic properties. Langmuir 2013, 29, 7134-7142, https://doi.org/10.1021/la400753q .

11. Kwon, S.J.; Bard, A.J. DNA analysis by application of Pt nanoparticle electrochemical amplification with single label response. J. Am. Chem. Soc 2012, 134, 10777-10779, https://doi.org/10.1021/ja304074f.

12. Roy, N.: Gaur, A.; Jain, A.; Bhattacharya, S.; Rani, V. Green synthesis of silver nanoparticles: an approach to overcome toxicity. Environ. Toxicol. Pharmacol 2013, 36, 807-812, https://doi.org/10.1016/j.etap.2013.07.005. 
13. Luo, X.; Morrin, A.; Killard, A.J.; Smyth, M.R. Application of nanoparticles in electrochemical sensors and biosensors. Electroanalysis 2006, 18, 319-326, https://doi.org/10.1002/elan.200503415.

14. Murthy, S.K. Nanoparticles in modern medicine: State of the art and future challenges. Int. J. Nanomed 2007, 2, 129-141.

15. Wen, Z.Q.; Li, G.; Ren, D. Detection of trace melamine in raw materials used for protein pharmaceutical manufacturing using surface-enhanced Raman spectroscopy (SERS) with gold nanoparticles. Appl. Spectrosc 2011, 65, 514-521, https://doi.org/10.1366/10-06089.

16. Xia, Y.; Yang, H.; Campbell, C.T. Nanoparticles for catalysis. Acc. Chem. Res 2013, 46, 1671-1672, https://doi.org/10.1021/ar400148q.

17. Sharma, D.; Kanchi, S.; Bisetty, K. Biogenic synthesis of nanoparticles: A review. Arabian J. Chem 2019, 12, 3576-3600, http://dx.doi.org/10.1016/j.arabjc.2015.11.002.

18. Sharma, D.; Kanchi, S.; Sabela, M.I.; Bisetty, K. Insight into the biosensing of graphene oxide: Present and future prospects. Arabian J. Chem 2016, 9, 238-261, https://dx.doi.org/10.1016/j.arabjc.2015.07.015.

19. Kanchi, S.; Kumar, G.; Lo, A.Y.; Tseng, C.M.; Chen, S.K.; Lin, C.Y.; Chin, T.S. Exploitation of de-oiled jatropha waste for gold nanoparticles synthesis: A green approach. Arabian J. Chem 2018, 11, 247-255, http://dx.doi.org/10.1016/j.arabjc.2014.08.006.

20. Sharma, D.; Sabela, M.I.; Kanchi, S.; Bisetty, K.; Skelton, A.A.; Honarparvar, B.. Green Synthesis, characterization and electrochemical sensing of silymarin by $\mathrm{ZnO}$ nanoparticles: Experimental and DFT studies. J. Electroanal. Chem 2018, 808, 160-172, https://doi.org/10.1016/j.jelechem.2017.11.039.

21. Sharma, D.; Sabela, M.I.; Kanchi, S.; Mdluli, P.S.; Singh, G.; Stenström, T.A.; Bisetty, K. Biosynthesis of $\mathrm{ZnO}$ nanoparticles using Jacaranda mimosifolia flowers extract: Synergistic antibacterial activity and molecular simulated facet specific adsorption studies. J. Photochem. Photobiol. B: Biol 2016, 162, 199-207, https://doi.org/10.1016/j.jphotobiol.2016.06.043.

22. Reddy Prasad, P.; Kanchi, S.; Naidoo. E.B. In-vitro evaluation of copper nanoparticles cytotoxicity on prostate cancer cell lines and their antioxidant, sensing and catalytic activity: One-pot green approach. $J$. Photochem. Photobiol. B: Biol 2016, 161, 375-382, http://dx.doi.org/10.1016/j.jphotobiol.2016.06.008.

23. Sabela, M.I.; Makhanya, T.; Kanchi, S.; Shahbaaz, M.; Idress, D.; Bisetty, K. One-pot biosynthesis of silver nanoparticles using Iboza Riparia and Ilex Mitis for cytotoxicity on human embryonic kidney cells. $J$. Photochem. Photobiol. B: Biol 2018, 178, 560-567, https://doi.org/10.1016/j.jphotobiol.2017.12.010.

24. Cruza, L.Y.; Wang, D.; Liu, J. Biosynthesis of selenium nanoparticles, characterization and X-ray induced radio therapy for the treatment of lung cancer with interstitial lung disease. J. Photochem. Photobiol. B: Biol 2019, 191, 123-127, https://doi.org/10.1016/j.jphotobiol.2018.12.008.

25. Anu, K.; Devanesan, S.; Prasanth, R.; AlSalhi, M.S.; Ajithkumar, S.; Singaravelu, G. Biogenesis of selenium nanoparticles and their anti-leukemia activity. J. King Saud Univer. Sci 2020, (In Press) https://doi.org/10.1016/j.jksus.2020.04.018.

26. Alam, H.; Khatoon, N.; Khan, M.A.; Husain, S.A.; Saravanan, M.; Sardar, M. Synthesis of selenium nanoparticles using probiotic bacteria lactobacillus acidophilus and their enhanced antimicrobial activity against resistant bacteria. J Clust Sci. 2019, (In Press), https://doi.org/10.1007/s10876-019-01705-6.

27. Alagesan, V.; Venugopal, J. Green synthesis of selenium sanoparticle using leaves extract of Withania somnifera and its biological applications and photocatalytic activities. Bio. Nano Sci 2019, 9, 105-116, https://doi.org/10.1007/s12668-018-0566-8.

28. Alfuraydi, A.A.; Devanesan, S.; Al-Ansari, M.; AlSalhi, M.S.; Ranjitsingh, A.J.A. Ecofriendly green synthesis of silver nanoparticles from the sesame oil cake and its potential anticancer and antimicrobial activities. J. Photochem. Photobiol. B: Biol 2019, 192, 83-89, https://doi.org/10.1016/j.jphotobiol.2019.01.011.

29. Xia, Y.; Tang, G.; Wang, C.; Zhong, J.; Chen, Y.; Hua, L.; Li, Y.; Liu, H.; Zhu, B. Functionalized selenium nanoparticles for targeted siRNA delivery silence Derlin1 and promote antitumor efficacy against cervical cancer. Drug Deliv 2020, 27, 15-25, https://doi.org/10.1080/10717544.2019.1667452.

30. 30. Valsalam, S.; Agastian, P.; Esmail, G.A.; Ghilan, A.K.M.; Al-Dhabi, N.A; Arasu, M.V. Biosynthesis of silver and gold nanoparticles using Musa acuminata colla flower and it pharmaceutical activity against bacteria and anticancer efficacy. J. Photochem. Photobiol., B: Biol 2019, 201, https://doi.org/10.1016/j.jphotobiol.2019.111670.

31. Saifi, M.A.; Sangomla, S.; Khurana, A. Protective effect of nanoceria on Cisplatin-induced nephrotoxicity by amelioration of oxidative stress and pro-inflammatory mechanisms. Biol. Trace .Elem. Res 2019, 189, 145-156, https://doi.org/10.1007/s12011-018-1457-0.

32. Li, H.; Liu, D.; Li, S.; Xue, C. Synthesis and cytotoxicity of selenium nanoparticles stabilized by $\alpha$-D-glucan from Castanea mollissima Blume. Int. J. Biol. Macromol 2019, 129, 818-826, https://doi.org/10.1016/j.ijbiomac.2019.02.085.

33. Khan, I.; Saeed, K.; Khan, I. Nanoparticles: Properties, applications and toxicities. Arabian J. Chem 2019, 12, 908-931. https://doi.org/10.1016/j.arabjc.2017.05.011.

34. Junejo, Y.; Safdar, M.; Akhtar, M.A. Synthesis of Tobramycin stabilized silver nanoparticles and its catalytic and antibacterial activity against pathogenic bacteria. J. Inorg Organomet Polym 2019, 29, 111-120, https://doi.org/10.1007/s10904-018-0971-z. 
35. Anand, K.; Rajamanikandan, R.; Selva Sharma, R.; Ilanchelian, M.; Iqbal Khan, F.; Tiloke, C.; Katari, N.; Boomi, P.; Balakumar, C.; Saravanan, M.; Palanisamy, S.; Ramesh, M.; Kun Lai, D.; Chuturgoon, A.A. Human serum albumin interaction, in silico and anticancer evaluation of Pine-Gold nanoparticles. Process Biochem 2020, 89, 98-109, https://doi.org/10.1016/j.procbio.2019.09.036.

36. Jin, Y.; Cai, L.; Yang, Q.; Luo, Z.; Liang, Li.; Liang, Y.; Wu, B.; Ding, L.; Zhang, D.; Xu, X.; Zhang, L.; Zhou, F. Anti-leukemia activities of selenium nanoparticles embedded in nanotube consisted of triple-helix $\beta$-D-glucan. Carbohydr.Polym 2020, 240, https://doi.org/10.1016/j.carbpol.2020.116329.

37. Menon, S.; Shrudhi Devi, K.S.; Agarwal, H.; Venkat Kumar, S. Efficacy of biogenic selenium nanoparticles from an extract of ginger towards evaluation on anti-microbial and antioxidant activities. Colloid Interfac. Sci 2019, 29, 1-8, https://doi.org/10.1016/j.colcom.2018.12.004.

38. Yazhiniprabha, M.; Vaseeharan, B. In vitro and in vivo toxicity assessment of selenium nanoparticles with significant larvicidal and bacteriostatic properties. Mater. Sci. Eng. C 2019, 103, https://doi.org/10.1016/j.msec.2019.109763.

39. Zhang, H.; Zhou, H.; Bai, J.; Li, Y.; Yang, J.; Ma, Q.; Qu, Y. Biosynthesis of selenium nanoparticles mediated by fungus Mariannaea sp. HJ and their characterization. Colloid Surf. A 2019, 571, 9-16, https://doi.org/10.1016/j.colsurfa.2019.02.070.

40. Dumore, N.S.; Mukhopadhyay, M. Antioxidant properties of aqueous selenium nanoparticles (ASeNPs) and its catalysts activity for 1,1-diphenyl-2-picry;hydrazyl (DPPH) reduction. J. Mol. Struct 2020, 1205, https://doi.org/10.1016/j.molstruc.2019.127637.

41. Shojaee, A,; Mostafavi, A.; Shamspur, T.; Fathirad, F. Green synthesis of cerium oxide nanoparticles:characterization, parameters optimization and investigation of photocatalytic application. Biointerface Res. Appl. Chem 2020, 10(4), 5932-5937. https://doi.org/10.33263/BRIAC104.932937

42. Husain, Q. An overview on the green synthesis of nanoparticles and other nanomaterials using enzymes and their potential applications. Biointerface Res. Appl. Chem 2019, 9(5), 4255-4271. https://doi.org/10.33263/BRIAC95.255271

43. Pathak, J.; Sonker, A.S.; Rajneesh.; Singh, V.; Kumar, D.; Sinha, R.P. Synthesis of silver nanoparticles from extracts of Scytonema geitleri HKAR-12 and their in vitro antibacterial and antitumor potentials. Lett. Appl. NanoBioSci 2019, 8(3), 576-585. https://doi.org/10.33263/LIANBS83.576585

44. Narasaiah, B.P.; Mandal, B.K. Bio-fabricated $\mathrm{CuO}$ NPs as green catalyst towards remediation of environmental pollutants. Lett. Appl. NanoBioSci 2019, 8(3), $597-603$. https://doi.org/10.33263/LIANBS83.597603

45. Nasrollahzadeh, M.; Zahraei, A.; Ehsani, A.; Khalaj, M. Synthesis, characterization, antibacterial and catalytic activity of a nanopolymer supported copper(II) complex as a highly active and recyclable catalyst for the formamidation of arylboronic acids under aerobic conditions. RSC Adv 2014, 4, 20351-20357, https://doi.org/10.1039/C4RA02052A.

46. Zhong, Z.; Subramanian, A.S.; Highfield, J.; Carpenter, K.; Gedanken, A. From Discrete Particles to spherical aggregates: A simple approach to the self-assembly of Au colloids. Chem. Eur. J 2005, 11, 14731478, https://doi.org/10.1002/chem.200400529.

47. Philip, D. Biosynthesis of Au, Ag and Au-Ag nanoparticles using edible mushroom extract. Spectrochim. Acta Mol. Biomol. Spectrosc 2009, 73, 374-381, https://doi.org/10.1016/j.saa.2009.02.037.

48. Bhat, R.; Sharanabasava, V.; Deshpande, R.; Shetti, U.; Sanjeev, G.; Venkataraman, A. Photo-bio-synthesis of irregular shaped functionalized gold nanoparticles using edible mushroom Pleurotus florida and its anticancer evaluation. J. Photochem. Photobiol. B: Biol 2013, 125, 63-69, https://doi.org/10.1016/j.jphotobiol.2013.05.002.

49. Boonsong, S.; Klaypradit, W.; Wilaipun, P. Antioxidant activities of extracts from five edible mushrooms using different extractants. Agri. Nat. Resour 2016, 50, 89-97, https://doi.org/10.1016/j.anres.2015.07.002.

50. 46. Reddy, N.J.; Vali, D.N.; Rani, M.; Rani, S.S. Evaluation of antioxidant, antibacterial and cytotoxic effects of green synthesized silver nanoparticles by Piper longum fruit. Mater. Sci. Eng. C 2014, 34, 115-122, https://doi.org/10.1016/j.msec.2013.08.039.

51. Pang, B.; Yan, J.; Yao, L.; Liu, H.; Guan, J.; Wang, H.; Liu, H. Preparation and characterization of antibacterial paper coated with sodium lignosulfonate stabilized $\mathrm{ZnO}$ nanoparticles. $R S C$ Adv 2016, 6, 97539759, https://doi.org/10.1039/C5RA21434C.

52. Li, X.; Xing, Y.; Jiang, Y.; Ding, Y.; Li, W. Antimicrobial activities of ZnO powder-coated PVC film to inactivate food pathogens. Int. J. Food Sci. Tech 2009, 44, 2161-2168, https://doi.org/10.1111/j.13652621.2009.02055.x.

53. Raghupathi, K.R.; Koodali, R.T.; Manna, A.C. Size-dependent bacterial growth inhibition and mechanism of antibacterial activity of zinc oxide nanoparticles. Langmuir 2011, 27, 4020-4028, https://doi.org/10.1021/la104825u. 